\title{
Van Tarım Meslek Lisesi Esmer Sığır Sürüsünün Genetik Analizi”
}

\author{
Ali KAYGISIZ1,
}

\author{
Yusuf VANLI ${ }^{2}$
}

Geliş Tarihi : 12.02.1997

\begin{abstract}
Özet : Bu çalışmada Van Tarım Meslek Lisesi Esmer sığır surusunün genetik analizi yapıımıştır.
Gerçek sut verimi, 305 günlak sôt verimi, ortalama gülük süt verimi, laktasyon süresi, buzağllama aralığı, servis peryodu ve gebelik süresinin kalitım dereceleri sırasıyla $0.359 \pm 0.059,0.356 \pm 0.059,0.254 \pm 0.0059,0.224 \pm 0.058,0.071 \pm 0.104$, $0.063 \pm 0.098$ ve $0.142 \pm 0.038$, 'ekrarlanma dereceleri ise yine aynı özellikler için $0.892 \pm 0.236,0.758 \pm 0.243,0.767 \pm 0.222$, $0.821 \pm 0.212,0.143 \pm 0.039,0.306 \pm 0.058$ ve $0.462 \pm 0.174$ olarak bulunmuştur.

Aynı hayvanların birbirini izleyen verimierini kullanarak çevresel yönelim $-29.90 \mathrm{~kg} / \mathrm{yll}$, fenotipik yönelim $\quad-16.95 \mathrm{~kg} / \mathrm{yil}$, genetik yönelim ise $+12.95 \mathrm{~kg} / \mathrm{yll}$ olarak gerçekleşmiştir.

Diğer yandan, uygulanmış olan seleksiyondan sot verimindeki genetik yönelim 1968-89 yllian arasında $+15.15 \mathrm{~kg} / \mathrm{y} ı \mathrm{l}$ olarak tahmin edilmiştir. Bu ilerlemenin \% 94.35'i boğa analarının seçiminden kaynaklanmıştır.
\end{abstract}

Anahtar kelimeler : Esmer sığır, genetik yönelim, kalıtım derecesi, tekrarlanma derecesi

\section{Genetic Analysis of the Brown Cattle Herd of Van Agricultural Vocational High School}

\begin{abstract}
The purpose of this study was to determine the genetic analysis of the Brown cattle herd of Van Agricultural Vocational High School.

The heritability estimates were $0.359 \pm 0.059,0.356 \pm 0.059,0.254 \pm 0.059,0.224 \pm 0.058,0.071 \pm 0.104,0.063 \pm 0.098$ and $0.142 \pm 0.038$ for lactation milk yield, 305 day milk yield, average daily milk yield, lactation period calving interval, service period and gestation period respectively. The repeatability estimates were $0.892 \pm 0.236,0.758 \pm 0.243,0.767 \pm 0.222,0.821 \pm 0.212$, $0.143 \pm 0.039,0.306 \pm 0.058$ and $0.462 \pm 0.174$ for the same traits.

By taking the weighed means for the years under the consideration, the phenotypic and environmental change per year was estimated as $-16.95 \mathrm{~kg}$ and $-29.90 \mathrm{~kg}$ respectively. The genetic change was calculated to be $12.95 \mathrm{~kg}$ per year according to the values given for the environmental and genetic trends.

On the other hand, the genetic trend in milk yield of cows in the herds from 1969 to 89 was estimated as $15.15 \mathrm{~kg} / \mathrm{year}$. About $94.35 \%$ of this gain came from the selection of dams of sires.
\end{abstract}

Key words : Brown cattle, genetic trend, heritability, repeatability

\section{Giriş}

Tarımın diğer dallarında olduğu gibi, zootekní faaliyetlerinin de temel amacı işletmelerin hayvancılıktan sağladığı ekonomik karlıığı arttırmaktır. Bu ise hayvanların fenotipik değerlerinin yâkseltilmesiyle mümkündür. Bir ferdin fenotipi, kendi genotipi ile içinde bulunduğu çevrenin ortak tesirlerinin bir sonucu olduğuna göre, yetiştirici için ekonomik önem taşıyan ıraların geliştirilmesi, hem sürüdeki hayvanların genotiplerinin ve hem de bu hayvanların içinde bulunduğu çevre şartlarının iyileştirilmesiyle başarılabilir. Uzun yıllardan beri bir yandan genotipin ıslahı, diğer yandan da çevre şartlarının iyileştirilmesini amaçlayan çalışmalar neticesinde her hayvan türünde daha yüksek ortalama değerler elde edilmiştir.
Belirli bir zaman sürecinde bir verim bakımindan sağlanan değişime fenotipik yönelim denir. Fenotipik yőnelim de genotipik yönelim ve çevresel yỏnelim olmak üzere iki unsurdan oluşmaktadır (Herbert ve Bhatnagar 1988). Özellikle hayvancilığı ileri ulkelerde uzun yıllardan beri yapılan sığır ıslahı çalışmaları sonucu verimde meydana gelen artışın genetik ve çevre kaynaklarından ne ölçüde etkilendiği konusunda bir çok çalışma bulunmaktadır. Çeşitli populasyonlarda elde edilen genetik yönelim tahminleri Çizelge 1 ve 2 'de verilmiştir.

Hayvan ıslahında yüksek verimli fertieri damızlığa ayırmak ve bunlara daha çok döl verme şansı tanımak suretiyle sürünün verim seviyesi yükseltilebilir. Yapılan bu işlem bir ıslah vasıtası olan

\footnotetext{
Aynr isimli doktora tezinden özetlenmiştir.

${ }_{1}^{1}$ Kahramanmaraş Sutcu Imam Üniv. Ziraat Fak. Zootekni Bölümü, Kahramanmaraş

${ }^{2}$ Trakya Univ. Ziraat Fak. Zootekni Bölama, Tekirdağ
} 
Çizelge 1. Birbirini izleyen verimler metodunu kullanarak elde edilen genetik yönelim $(\mathrm{kg} / \mathrm{y}$ il) tahminleri

\begin{tabular}{|c|c|c|}
\hline Irk & $\begin{array}{c}\text { Genetik } \\
\text { Yönelim }\end{array}$ & Kaynak \\
\hline Esmer & -53.6 & Akar ve Pekel (1988) \\
\hline Esmer & $156-158$ & Lak (1987) \\
\hline Siyah Alaca & -34.5 & Johnson ve ark.(1956) \\
\hline Siyah Alaca & -8.1 & Gaalas ve Plowman (1961) \\
\hline Siyah Alaca & 0.309 & Dillon ve ark.(1955) \\
\hline Siyah Alaca & $70-78$ & Siyam ve Düzgüneș (1984) \\
\hline Siyah Alaca & 71.7 & Mc Daniel ve ark.(1961) \\
\hline Siyah Alaca & 149 & Gürdoğan ve Alpan (1990) \\
\hline Jersey & -12.3 & Johnson ve ark.(1956) \\
\hline Jersey & $7.4-84.5$ & Arave ve Laben (1963) \\
\hline Jersey & 33.6 & Arave ve ark.(1964) \\
\hline
\end{tabular}

Çizelge 2. Uygulanmış olan seleksiyon sonuçlarından elde edilen genetik yönelim tahminleri (GY) (kg/yil) ve generasyon aralıkları (GA) (yıl)

\begin{tabular}{|c|c|c|c|}
\hline Irk & GA & GY & Kaynak \\
\hline Esmer & 5.3 & 0.59 & Yener (1979) \\
\hline Esmer & 5.9 & 150 & Lak (1987) \\
\hline Siyah Alaca & 4.2 & -2.3 & Yener ve ark.(1978) \\
\hline Siyah Alaca & - & 92 & Güroğan ve Alpan (1990) \\
\hline Ayrshire & & 15.45 & Rendel ve Robertson (1950) \\
\hline Ayrshire & - & $30-37$ & Lindstorm (1968) \\
\hline N.KırmızISI & 6 & 34.32 & Syrstad (1966) \\
\hline N.KIrmızıs। & 6.2 & 47.17 & Syrstad (1966) \\
\hline Haryana & 7.9 & 16 & Acharya ve Lush(1968) \\
\hline Red Sindhi & 6.5 & -11.71 & Mahadevan (1955) \\
\hline Çek Alaca & 6.8 & 21.97 & Siler ve Sereda (1971) \\
\hline Brezilya & 7.0 & - & Brasil ve ark.(1990) \\
\hline Yerli Mısır & - & 8.2 & Asker ve ark.(1955) \\
\hline
\end{tabular}

seleksiyondur. Seleksiyona karar verirken ve uygulama esaslarını tespit edip planlarken sürüye ait baz̈ı parametrelerin bilinmesine intiyaç vardır.
Bir vasıf bakımından yapılacak seleksiyonla sağlanabilecek ilerlemenin tahmini için kalıtım derecesinin, seleksiyonun yapılacağı yaşı ve hayvanın beklenen (gerçek) verim kabiliyetinin tahmini için tekrarlanma derecesinin ve bir vasif bakımından yapılacak seleksiyonun diğer vasıflara tesir şekil ve derecesinin tahmini içinde vasıflar arası genetik korelasyonun bilinmesi gerekir (Vanlı ve ark.1993). Çeşitli Esmer sığır populasyonlarında süt verim özellikleri [gerçek süt verimi (GSV), 305 günlük süt verimi (305 GSV), ortalama günlük süt verimi (OGSV), laktasyon süresi (LS)] ve döl verim özellikleri [buzağılama aralığı $(B A)$, servis peryodu (SP) ve gebelik süresi (GS)] için hesaplanan kalitim derecesi tahminleri Çizelge 3 , tekrarlanma derecesi tahminleri ise Çizelge 4 'de verilmiştir.

Esmer sığırlarla yürütülen bu çalışmada (i) 305 günlük süt veriminde meydana gelen genetik yönelimlerin farklı metodlarla tahmin edilmesi ve (ii) süt ve döl verim özelliklerine ait bazı genetik parametrelerin tahmin edilmesi amaçlanmıştır.

\section{Materyal ve Yöntem}

\section{Materyal}

Araştırmanın hayvan materyalini Van Tarım Meslek Lisesi işletmesine 1967 yılında Sarımsaklı Devlet Üretme Çiftliğinden getirilen 9 düve, 1 boğa ile 1976 yılında Avusturya'dan getirilen 10 baş inek ve bunların dişi yavrularının 1968-92 yılları arasındaki süt ve döl verim kayıtları oluşturmuştur. Kalıtım derecesinin tahmininde 45 boğanın 1-8. laktasyon sırasındaki 110 kızına ait 387 adet laktasyon değerlendirilmiştir. Genetik yönelimlerin hesaplanmasında ise $1968-89$ yıllarındaki 85 baş ineğe ait 343 adet laktasyon kaydı kullanılmıştır.

Çizelge 3. Esmer sığırlarda süt ve döl verim özelliklerine ilişkin kalıtım derecesi tahminleri

\begin{tabular}{|c|c|c|c|c|c|c|c|}
\hline GSV & 305 GSV & OGSV & LS & BA & SP & GS & Kaynak \\
\hline & $-0.02 / 2.15$ & & & & & & Yener (1979) \\
\hline & 0.52 & & & & & & Lak (1987) \\
\hline & 0.23 & & & & & & Akar ve Pekel (1988) \\
\hline & 0.34 & 0.50 & -0.08 & & & & Akbulut (1990) \\
\hline & $0.45-0.52$ & & & & & & Gürdoğan ve Alpan (1990) \\
\hline $0.36-0.68$ & & & $0.56-0.84$ & & & & Ulusan ve Ozçelik (1988) \\
\hline & & & 0.011 & 0.037 & 0.023 & & Juma ve ark.(1990) \\
\hline & & & & 0.12 & & & Meija ve ark.(1982) \\
\hline
\end{tabular}


Çizelge 4. Esmer sığırlarda sût ve döl verim äzelliklerine ilişkin tekrarlanma derecesi tahminleri

\begin{tabular}{|c|c|c|c|c|c|c|c|}
\hline GSV & $305 \mathrm{SV}$ & OGSV & LS & BA & SP & GS & Kaynak \\
\hline & $-0.04 / 0.59$ & & & & & & Yener (1979) \\
\hline & 0.48 & & & & & & Lak (1987) \\
\hline & 0.33 & & & & & & Akar ve Pekel (1988) \\
\hline & 0.37 & 0.35 & 0.09 & & & & Akbulut (1990) \\
\hline & $0.50-0.56$ & & & & & & Gürdoğan ve Alpan (1990) \\
\hline & $0.29-0.30$ & & $0.13-0.27$ & & & & Ulusan ve Özçelik (1988) \\
\hline $0.51-0.75$ & & & & & & & Pysheckin (1988) \\
\hline & & & & 0.32 & & & Meija ve ark.(1982) \\
\hline & & & & 0.19 & 0.17 & 0.22 & Inal (1988) \\
\hline & & & & & & 0.17 & Oishi ve ark.(1983) \\
\hline
\end{tabular}

\section{Yöntem}

Kontrol günü verimlerinden laktasyon süt veriminin hesaplanmas!

Işletmede süt kontrolleri haftalık olarak yapılmıştır. Bu nedenle, laktasyon süt veriminin hesaplanmasında 7 gunnlük kontrol aralığında en az hatalı tahmini yaptığı bildirilen (Talan, 1989) Tarım Işletmeleri Metodu kullanılmıştır. Bu metoda göre, süt kontrolleri ineğin buzağılamasından dört gün sonra başlamış, ineğin kuruya çıkışına kadar devam etmiştir. Kontrol günü tespit edilen verim, bir önceki kontrolden itibaren geçen gün sayısı ile çarpılarak haftalık verimler, haftalık verimlerde toplanarak aylık verimler, aylık verimlerde toplanarak toplam laktasyon verimi hesaplanmıştır.

\section{Genetik parametrelerin tahmini}

Genetik parametrelerin tahmininde verim özelliğine etkili çevre faktörlerini de dikkate alan ve genel ifadesi aşağıda verilen karışık model (Mixed Model) esas alınmıştır.

$Y_{i j k}=\mu+s_{i}+f_{i}+e_{i j k}$ Model 1

Bu modelde; $Y_{i j k}=$ Ele alınan verim özelliğine ait gözlem değerini, $\mu=$ populasyon ortalamasını, $s_{i}=i$. boğa veya ineğe ait eklemeli etki'yi $(i=1,2, \ldots, s), f_{j}=$ Tüm sabit etkileri $(j=1,2, \ldots . f)$, eijk $=$ Ortalaması 0 ve varyansı $s^{2}$ olan şansa bağlı hata'yı göstermektedir (Harvey, 1987).

Buna göre kalıtım derecesi ve tekrarlanma derecesinin tahmininde aşağıda verilen matematik modeller kullanılmıştır;

Süt verim özellikleri için ;

$Y_{i j k m n}=\mu+a_{i}+b_{i}+c_{k}+s_{m}+e_{i j k m n}$
Gebelik süresi için;

$Y_{i j l m n}=\mu+a_{i}+b_{j}+d_{i}+s_{m}+e_{i j l m n}$

Buzağılama aralığı ve servis peryodu için;

$Y_{i j m n}=\mu+a_{i}+b_{j}+s_{m}+e_{i j m n}$

Bu modellerde yer alan terimlerden ; $Y=$ Herhangi bir ineğin, ele alınan herhangi bir süt veya döl verim özelliğini, $\mu=$ Populasyonun beklenen ortalamasını, $a_{i}=i$. verim yılının etki miktarını, (i: 1968...1992), $b_{j}=j$. laktasyon veya doğum sırası etki miktarını, (1...8. doğum), $\mathrm{c}_{\mathrm{k}}=\mathrm{k}$. mevsimin etki miktarını, [k: 1(kıs), 2(ilkbahar), 3 (yaz), 4(sonbahar)], $d_{1}=$ I. buzağı cinsiyeti etki miktarını, $s_{m}=m$. boğa veya inek etki miktarını, $e=$ normal, bağımsız ve şansa bağlı hata' yı temsil etmektedir.

Tekrarlanma derecesinin tahmininde en az iki laktasyon kaydı bilinen ineklerin bu verimlerinin benzerliğinden (grup içi korelasyon katsayısı), kalıtım derecesinin tahmininde ise baba-bir üvey kardeşler benzerliğinden yararlanımıștır. Kalıtım derecesi tahmininde en az iki yavrusunun verimi bulunan boğalar hesaplamaya katılmıştır. Buna göre yapılan variyans analiziyle grup-içi korelasyon metoduna göre hesaplanan variyans unsurları kullanılarak;

Tekrarlanma derecesinin tahmini, $\mathbf{s}_{\mathrm{a}}^{2}$ analar (inekler) arası variyansı göstermek üzere,

$r=\frac{s_{a}^{2}}{s_{a}^{2}+s_{e}^{2}}$

Kalıtım derecesinin tahmini, $\mathbf{s}^{2}{ }_{b}$ babalar (boğalar) arası variyansı göstermek üzere,

$h^{2}=\frac{4 s_{b}^{2}}{s_{b}^{2}+s_{e}^{2}}$ 
formülleri ile yapılmıştır (Vanlı ve ark.(1993). Hesaplamalarda Harvey (1987) tarafından yazılan "LSMLMM" program kullanılımıştır.

\section{Damızlık değerlerinin hesaplanması}

305 günlük süt verimi bakımindan damızık değerlerinin hesaplanmasında Harvey (1987) tarafından yazılan "LSMLMM" program kullanılmıștır. İnek damızlık değerlerinin hesaplanmasında hayvanin kendi verimi, boğa damızlık değerlerinin hesaplanmasında ise kızlarının verimleri dikkate alınmıştır.

Damızlık değerlerinin hesaplanmasında bireysel hayvan modeli (BHM) benimsenmiştir. $\mathrm{Bu}$ modellerde boğa ve ineklerin ortak, yani bir arada değerlendirilmesi mümkündür. Söz konusu BHM modeli;

$Y_{i j k}=\mu+h_{i}+a_{j}+p_{j}+e_{i j k}$ olarak yazılabilir, $B u$ modellerde sabit etkiler olarak $\mu$ ve $h$ etkisinin bulunduğu görülmektedir. Ancak istenildiğinde model içine diğer sabit etkilerinde ilave edilmesi mümkündür. Modelde yer alan terimlerden; $\mu=$ genel ortalama etki olup $E\left(Y_{i j k}\right)=\mu$ $+h_{i}, h_{i}=i$. yil etki miktarını, $a_{j}=$, hayvana ait eklemeli genetik etki miktarını, $p_{k}=j$. hayvana ait eklemeli sabit çevre etkisini, $e_{i j k}=$ geçici çevre etkisi veya hata'yı ifade etmektedir.

BHM modelinin matris gösterimi ile genel ifadesi, beklenen değerler ve variyans-kovariyans matrisleri aşağıdaki gibi yazılabilir;

$$
Y=X_{b}+Z_{d}+Z_{p}+e
$$

$E(y)=X b$

$$
\begin{array}{lll}
E(a)=0 & V(a)=A \sigma^{2} a & \operatorname{Cov}\left(a, p^{\prime}\right)=0 \\
E(p)=0 & V(p)=1 \sigma^{2}{ }_{p} & \operatorname{Cov}\left(a, e^{\prime}\right)=0 \\
E(e)=0 & V(a)=1 \sigma^{2} a & \operatorname{Cov}\left(p, e^{\prime}\right)=0
\end{array}
$$

Böylece, BHM'ye ait karışık model eşitliklerı (KME) genel bir şekilde aşağıdaki gibi yazılabilir;

$\left|\begin{array}{ll}X^{\prime} X & X^{\prime} Z \\ Z^{\prime} X & Z^{\prime} Z+\left(\sigma^{2}{ }_{e} / \sigma^{2} s\right.\end{array}\right| \quad\left|\begin{array}{l}b \\ u\end{array}\right| \quad\left|\begin{array}{l}X^{\prime} Y \\ Z^{\prime} Y\end{array}\right|$

$X^{\prime} X b+X^{\prime} Z u=X^{\prime} Y$

$Z^{\prime} X b+\left(Z^{\prime} Z+\left[\left(\sigma^{2} e^{\prime} / \sigma^{2} s\right)\right] U=Z^{\prime} Y\right.$

$u=\left[Z^{\prime} Z+\left(\sigma^{2} e^{\prime} \sigma^{2} s\right)^{-1}\left(Z^{\prime} Y-Z^{\prime} X b\right)\right.$

bu modellerde yer alan terimlerden,

$u=$ damızlık değerlerini,

$Z=$ şansa bağlı etkiler için desen matrisini,

$\sigma^{2}{ }_{\mathrm{e}}=$ boğa veya inek variyansını,

$Y=$ gözlem değerini, $\mathrm{b}=$ sabit etkilere ait katsayı vektörünü,

$X=$ sabit etkilere ait desen matrisini temsil etmektedir.

\section{Yönelim unsurlarının hesaplanması}

Süt sığırlarında yönelim unsurlarının hesaplanması için çeşitli metodlar geliştirilmiştir. Ancak bu metodlardan aşağıda açıklanan ikisi bu araştırmanın materyaline uygun niteliktedir.

\section{Birbirini izleyen verimler yolu ile yönelim unsurlarının hesaplanması}

Aynı hayvanların birbirini izleyen verimleri kullanılarak bulunan çevresel yönelim fenotipik yönelimden çıkarılmak suretiyle genetik yönelim hesaplanmıştır. Bu amaçla önce laktasyon sırası ve mevsim etkilerine göre düzetilmiş laktasyon verimlerinin ortalaması yıllara göre sıralanarak fenotipik yönelim bulunmuştur. Sonra birbirini izleyen iki yılda verimi bulunan ineklerin sıra ve mevsime göre düzeltilmiş birinci yıldaki verimlerinin ortalaması ile ikinci yıldaki verimlerinin ortalaması arasındaki fark alınmış ve bu, Söz konusu iki yıl arasındaki çevresel yönelimin tahmini olarak kabul edilmiştir. Bulunan bu değerler fenotipik yönelimden çıkarılarak 1968-1989 yılları arasındaki genetik yönelimler bulunmuştur.

\section{Uygulanmış olan seleksiyon sonuçlarına göre yönelim unsurlarının hesaplanması}

Üzerinde çalışılan sürüde, Rendel ve Robertson'un (1950), önerdiği analitik metod kullanılarak süt verimindeki genetik yönelim hesaplanmıştır. Önce bu araştırıcılar tarafından geliştirilen formülün terimleri tahmin edilmiştir. Formül aşağıdaki gibidir.

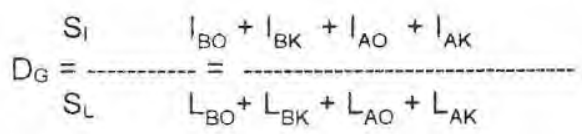

Burada;

$I_{B O}=$ Oğulları damızlık olarak kullanılan boğaların ortalama genetik üstünlüğü

$I_{B K}=$ Sürüdeki ineklerin babası olan boğaların ortalama genetik üstünlüğü

$I_{A O}=$ Oğulları damızlık olarak kullanılan anaların ortalama genetik üstünlüğü

$I_{A K}=$ Kızları damızlık olarak kullanılan anaların ortalama genetik üstünlüğü

$L_{B O}, L_{B K}, L_{A O}$ ve $L_{A K}$ ise sırasıyla babalar ile oğullar, analar ile kızlar, analar ile oğullar ve analar ile kızlar arasındaki yıl olarak ortalama generasyon aralıklarıdır. 


$$
\mathrm{I}_{\mathrm{BO}} \text { ve } \mathrm{L}_{\mathrm{BO}} \text { 'nun hesaplanması }
$$

Her boğanın damızlık değeri hesaplanmış, boğaların oğullarının sürüdeki kız sayısı tartı faktörü olarak kullanılarak damızlık değerlerinin tartilı ortalaması alınmış ve $I_{\text {Bo }}$ bulunmuştur. Oğulları doğduğunda babaların yaşları hesaplanmış ve bunların tartılı ortalaması $\mathrm{L}_{\mathrm{BO}}$ değerini vermiştir.

\section{$I_{\mathrm{BK}}$ ve $\mathrm{L}_{\mathrm{BK}}$ 'nın hesaplanması}

Sürüdeki mevcut ineklerin babalarının damızlık değerleri hesaplanarak, her boğanın kız sayısı tartı faktörü olarak kullanilarak damızlık değerlerinin tartılı ortalaması alınmış ve $\mathrm{I}_{\mathrm{BK}}$ bulunmuştur. Kızları doğduğunda babaların ortalama yaşlarının tartılı ortalaması alınmak suretiyle $\mathrm{L}_{\mathrm{BK}}$ değeri hesaplanmıştır.

\section{$I_{A O}$ ve $L_{A O}$ 'nun hesaplanması}

Her ananın damızlık değeri hesaplanmış ve oğullarının sürüde verimi olan kızlarının sayısı tartı faktörū olarak kullanılarak. I $I_{A O}$ değeri; oğullan doğduğunda analarının ortalama yaşlarının tartılı ortalamaları alınmak suretiyle de $L_{A O}$ değeri hesaplanmıştır.

$$
I_{A K} \text { ve } L_{A K} \text { 'nin hesaplanması }
$$

Sürodeki anaların damızlık değerleri hesaplanarak, her ananın kız sayısı tartı faktörù olarak kullanılarak damızlık değerlerinin tartılı ortalaması alınmış ve $I_{A K}$ tahmin edilmiştir. Kızları doğduğunda anaların yaşları hesaplanmış, bunların tartılı ortalaması alınmak suretiyle de $L_{\text {AK }}$ bulunmuştur.

\section{Bulgular ve Tartışma}

\section{Genetik parametre tahminieri}

\section{Süt verim özellikleri}

Süt verim özelliklerine ait kalıtım derecesi tahminleri Çizelge 5'de verilmiştir.

Çizelge 5. Sot verim özelliklerine ait kalıtım ve tekrarlanma dereceleri ve standart hatalari

\begin{tabular}{|c|c|c|}
\hline Verim Özelliği & $h^{2}$ & $r$ \\
\hline Gerçek Săt Ver. & $0.359 \pm 0.059$ & $0.892 \pm 0.236$ \\
\hline 305 Ganiak Sat Ver. & $0.356 \pm 0.059$ & $0.758 \pm 0.243$ \\
\hline Ort. Ganlök Sät Ver. & $0.254 \pm 0.059$ & $0.767 \pm 0.222$ \\
\hline Laktasyon Săresi & $0.224 \pm 0.058$ & $0.821 \pm 0.212$ \\
\hline
\end{tabular}

Gerçek süt verimine ilişkin kalıtım derecesi $0.359 \pm 0.059$, olarak tahmin edilmiştir. Bu değer Ulusan ve Özçelik (1988) tarafından Avusturya Esmerlerinde bildirilen 0.36 değerlerine oldukça yakın bulunmuştur. Buna karşılık Ulusan ve Özçelik (1988)'in Eskişehir Esmerleri için bildirdiği 0.68 değerleri bu araştırmada elde edilen değerden daha yüksektir.

305 günlük süt verimine ilişkin kalıtım derecesi $0.356 \pm 0.059$ olarak tahmin edilmiştir. Bu değer, Türkiye'de yapılan araştırmalarda ise Malya, Koçaş, Polatlı, Çiçekdağ, Konuklar ve Gözlü D.Ü.Ç'lerindeki Esmer sığırlarda $0.66,0.22,2.15,0.54,0.14$ ve -0.02 (Yener 1979), Ankara Şeker Fabrikası Civar Çiftliğinde yetiştirilen Siyah Alaca ve Esmerlerde sırasıyla 0.45 \pm 0.19 (Gürdoğan ve Alpan, 1990) ve 0.52 (Lak 1987), Atatürk Universitesi Ziraat işletmesinde yetiştirilen Esmerlerde 0.34 (Akbulut 1990) olarak bildirilmiştir. Bu araştırmada elde edilen $0.356 \pm 0.059$ değeri yukarıda bildirilen değer aralığının içinde yer almaktadır.

Ortalama günlük süt verimine ilişkin kalıtım derecesi $0.254 \pm 0.059$ olarak tahmin edilmiştir. Bu değer, Akbulut (1990) tarafından Esmer sığırlar için bildirilen 0.50 değerlerinden düşük, Gönül ve Vos'un (1966) Siyah Alacalar için baba bir üvey kardeş korelasyonuna göre; düzeltilmemiş verilerden hesapladığı 0.20 , düzeltilmiş verilerden hesapladığı 0.23 değerlerine benzer bulunmuştur.

Laktasyon süresine ilişkin kalıtım derecesi $0.224 \pm 0.058$ olarak tahmin edilmiştir. Bu değer, Irakta yetiştirilen Esmerler için bildirilen 0.011 (Juma ve ark. 1990), Erzurum'da yetiştirilen Esmerler için bildirilen $0.08 \pm 0.10$ (Akbulut 1990) değerlerinden yöksek, Eskişehir'de yetiştirilen Eskişehir ve Avusturya Esmerleri için bildirilen 0.84 ve 0.56 (Ulusan ve Özçelik 1988) değerlerinden ise dūşük bulunmuştur.

Gerçek süt veriminin tekrarlanma derecesi için hesaplanan $0.892 \pm 0.236$ değeri genellikle diğer araştırıcılar tarafından çeşitli ırklarda bildirilen tekrarlanma derecesi tahminlerinden yüksektir.

Aynı değer Eskişehir'de yetiştirilen Esmerlerde 0.33 (Akar ve Pekel 1988), Rus Esmerlerinde 0.51-0.75 (Pyshechkin 1988) olarak tahmin edilmiştir. Bütün bu sonuçlara göre; bu araştırma materyalinin gerçek süt veriminin tekrarlanma derecesi bakımından yüksek bir değere sahip olduğu anlaşılmaktadır.

305 günlük süt verimi için $0.758 \pm 0.243^{\prime} \mid u ̈ k$ tekrarlanma derecesi tahmin edilmiştir. Aynı değerin Malya, Koçaş, Polatı, Çiçekdağ, Konuklar ve Gơzlü Devlet Üretme Çiftliklerindeki Esmerlerde 0.33, 0.38, 
$0.59,0.43,0.33$ ve -0.04 (Yener 1979), Ankara Şeker Çiftliğinde yetiştirilen Esmer sığırlarda $0.48 \pm 0.04$ (Lak 1987), Erzurum'da yetiştirilen Esmerlerde $0.37 \pm 0.07$ (Akbulut 1990), Eskişehir Şeker Fabrikası çiftliğinde yetiştirilen Avusturya Esmerlerinde 0.29, Eskişehir Esmerlerinde 0.30 (Ulusan 1988) olarak bildirildiği gözönüne alındığında bu araştırmada elde edilen tekrarlanma derecesi tahmininin yüksek değere sahip olduğu anlaşıiır.

Ortalama günlük süt verimi için $0.767 \pm 0.222$ olarak elde edilen tekrarlanma derecesi tahmini Esmer sığıllarda elde edilen 0.50 (Akbulut 1990) değerlerinden daha yüksek bulunmuştur.

Laktasyon süresinin tekrarlanma derecesi $0.821 \pm 0.212$ olarak tahmin edilmiştir. Bu değer, Avusturya ve Eskişehir Esmerlerinde elde edilen 0.13 ve 0.27 (Ulusan 1988) değerlerinden daha yüksektir.

\section{Döl verim özellikleri}

Döl verim özelliklerine ait kalitım derecesi tahminleri Çizelge 6'da verilmiştir.

Buzağılama aralığına ilişkın kalıtım derecesi $0.071 \pm 0.104$ olarak tahmin edilmiştir. Literatürde buzağılama aralığının kalıtım derecesi Irak'ta yetiştirilen Esmer sığırlarda 0.037 (Juma ve ark. 1990), Honduras'ta yetiştirilen Esmer sığırlarda 0.12 \pm 0.13 (Meija ve ark. 1982), Konya'da yetiştirilen Esmer sığırlarda $0.07 \pm 0.23$ (Inal 1988) olarak bildirilmiştir. Bu araștırmada elde edilen $0.071 \pm 0.104$ değeri yukarıda bildirilen değer aralığının alt sınırına daha yakın bulunmuștur.

Servis peryoduna ilişkin kalıtım derecesi $0.063 \pm 0.098$ olarak tahmin edilmiştir. Aynı özelliğe ait değerler Irak'ta yetiştirilen Esmerlerde 0,023 (Juma ve ark.1990), Konya'da yetiştirilen Esmerlerde $0.58 \pm 0.35$ (Inal 1988) olarak elde edilmiştir.

Gebelik süresinin kalıtım derecesi $0.142 \pm 0.038$ olarak tahmin edilmiştir. Bu değer, Konya Hayvancılık Merkez Araştırma Enstitüsünde yetiştirilen Esmer sığırlarda ise $0.45 \pm 0.16$ (Ínal 1988) olarak bildirilmiştir.

Çizelge 6. Döl verim özelliklerine ait kalıtım ve tekrarlanma dereceler ve standart hataları

\begin{tabular}{|c|c|c|}
\hline Verim Özelliği & $h^{2}$ & $r$ \\
\hline Buză̆ılama Aralığı & $0.071 \pm 0.104$ & $0.143 \pm 0.039$ \\
\hline Servis Peryodu & $0.063 \pm 0.098$ & $0.306 \pm 0.058$ \\
\hline Gebelik Suresi & $0.142 \pm 0.038$ & $0.462 \pm 0.174$ \\
\hline
\end{tabular}

Bu araştırmada gebelik süresi için elde edilen $0.14 \pm 0.04$ 'iük kalıtım derecesinin yukarıda verilen literatür bilgilerine göre bir değerlendirmesi yapıldığında; bu araştırmada elde edilen tahminle çoğu literatür bilgileri arasında benzerlik olduğu göze çarpmaktadır.

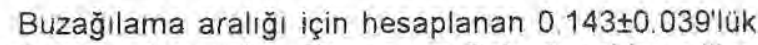
tekrarlanma derecesi, Esmer sığırlarda elde edilen $0.32 \pm 0.16$ (Meija ve ark. 1982) ve 0.19 (Inal 1988) değerlerinden daha düşük bulunmuştur.

Servis peryodu için elde edilen $0.306 \pm 0.058^{\prime}$ lik tekrarlanma derecesi Inal (1988) tarafindan Esmer sığırlar için bildirilen 0.17 değerinden daha yüksek bulunmuştur.

Gebelik süresi için elde edilen $0.462 \pm 0.174^{\prime}$ lük tekrarlanma derecesi, Japon Esmerlerinde elde edilen 0.17 (Oishi ve ark.(1983) ve Konya'da yetiştirilen Esmerlerde elde edilen 0.22 (Inal 1988) değerlerinden yüksek bulunmuştur.

\section{Yönelim unsurlarının tahmini}

\section{Birbirini izleyen verimler yolu ile yönelim unsurlarının tahmini}

Araştırmada ele alınan fenotipik, çevresel ve genetik yönelimlerin tahmininde laktasyon sırası ve buzağılama mevsimi bakımından düzeltilmiş 305 günlük süt verimlerinin yıllık ortalamaları kullanılmıştır. Bu amaçla 1967-1989 yılları arasında elde edilen 305 günlük süt verim ortalamaları, birbirini izleyen yıllar arasındaki farklar ve bunların eklemeli değerleri ile her bir yıla ait laktasyon sayıları Çizelge 7'de verilmiştir. Fenotipik yönelimin çevresel ve genetik unsurlarını hesaplamak için aynı hayvanlarin birbirini izleyen iki yıldaki verimleri arasındaki farklılıklardan yararlanıimıştır. Burada bir hayvanın her yıl gösterdiği fenotipik değerde aynı genetik faktörlerin rol oynadığı kabul edilmiş ve bu yıllar arasında gözlenen farkın çevre faktörlerinin değişmesinden ileri geldiği (çevresel yönelim) varsayılmıştır. Çevresel yöneliminide fenotipik yönelimden çıkararak genetik yönelim hesaplanmıştır. Söz konusu yıllara ait fenotipik, çevresel ve genetik yönelim tahminleri Çizelge 7 ve Şekil 1 'de verilmiştir.

Çizelge'nin incelenmesinden de anlaşılacağı gibi 305 günlük süt veriminde birbirini izleyen yıllarda gayr! muntazam iniş-çıkışlar meydana gelmiştir. En düşük fenotipik yönelim $1977-78$ yılları arasında $-329 \mathrm{~kg}$, en yüksek fenotipik yönelim ise 1983.84 yilları arasında $+758 \mathrm{~kg}$ olarak gerçekleșmiştir. Düzeltilmiş ortalamalara ait farkların toplamı $-356 \mathrm{~kg}$, bu artışın yıla düşen miktar ise $-16.95 \mathrm{~kg}$ 'dır. 
Çizelge 7. 305 ganlök sŭ verimindeki fenotipik, çevresel ve genetik yönelimin hesaplanması

\begin{tabular}{|c|c|c|c|c|c|c|c|c|}
\hline \multirow[t]{2}{*}{ Yillar } & \multicolumn{3}{|c|}{ Fenotipik } & \multicolumn{3}{|c|}{ Cevresel } & \multicolumn{2}{|c|}{ Genetik } \\
\hline & $\mathrm{N}$ & Yillik & Eklemeli & $\mathrm{N}$ & Yillik & Eklemeli & Yillik & Eklemeli \\
\hline 1968-69 & 7 & -160 & -160 & 2 & -257 & -257 & +97 & +97 \\
\hline $1969-70$ & 10 & +109 & -51 & 2 & +19 & -238 & +90 & +187 \\
\hline $1970-71$ & 14 & -238 & -289 & 9 & -492 & -730 & +254 & +441 \\
\hline $1971-72$ & 7 & -52 & -341 & 8 & +108 & -622 & -160 & +281 \\
\hline $1972-73$ & 16 & +62 & -279 & 6 & +146 & -476 & -84 & +197 \\
\hline $1973-74$ & 22 & +57 & -222 & 13 & -8 & -484 & +65 & +262 \\
\hline $1974-75$ & 19 & -147 & -369 & 14 & -132 & -616 & -15 & +247 \\
\hline $1975-76$ & 17 & -184 & -553 & 14 & -73 & -689 & -111 & +136 \\
\hline $1976-77$ & 20 & +14 & -539 & 11 & +196 & -493 & -182 & -46 \\
\hline $1977-78$ & 21 & -329 & -868 & 14 & -550 & -1043 & +251 & +205 \\
\hline $1978-79$ & 22 & +232 & -636 & 15 & +249 & -794 & -17 & +188 \\
\hline $1979-80$ & 20 & +36 & -600 & 12 & -49 & -843 & +85 & +243 \\
\hline $1980-81$ & 25 & +293 & -307 & 10 & +288 & -555 & +5 & +248 \\
\hline 1981-82 & 19 & -456 & -763 & 7 & -306 & -861 & -150 & +98 \\
\hline $1982-83$ & 29 & +89 & -674 & 11 & +39 & -822 & +50 & +148 \\
\hline $1983-84$ & 15 & +758 & +86 & 14 & +822 & 0 & -64 & +84 \\
\hline 1984-85 & 8 & +27 & +111 & 7 & -70 & -70 & +97 & +181 \\
\hline $1985-86$ & 7 & -259 & -148 & 3 & -352 & -422 & +93 & +274 \\
\hline $1986-87$ & 11 & -80 & -228 & 4 & +25 & -397 & -105 & +169 \\
\hline $1988-88$ & 14 & -318 & -546 & 4 & -454 & -851 & +136 & +305 \\
\hline $1988-89$ & 18 & +190 & -356 & 9 & +223 & -628 & -33 & +272 \\
\hline Ortalama & \multicolumn{3}{|c|}{$(-16.95)$} & \multicolumn{3}{|c|}{$(29.90)$} & \multicolumn{2}{|c|}{$272 / 21=12.95$} \\
\hline
\end{tabular}

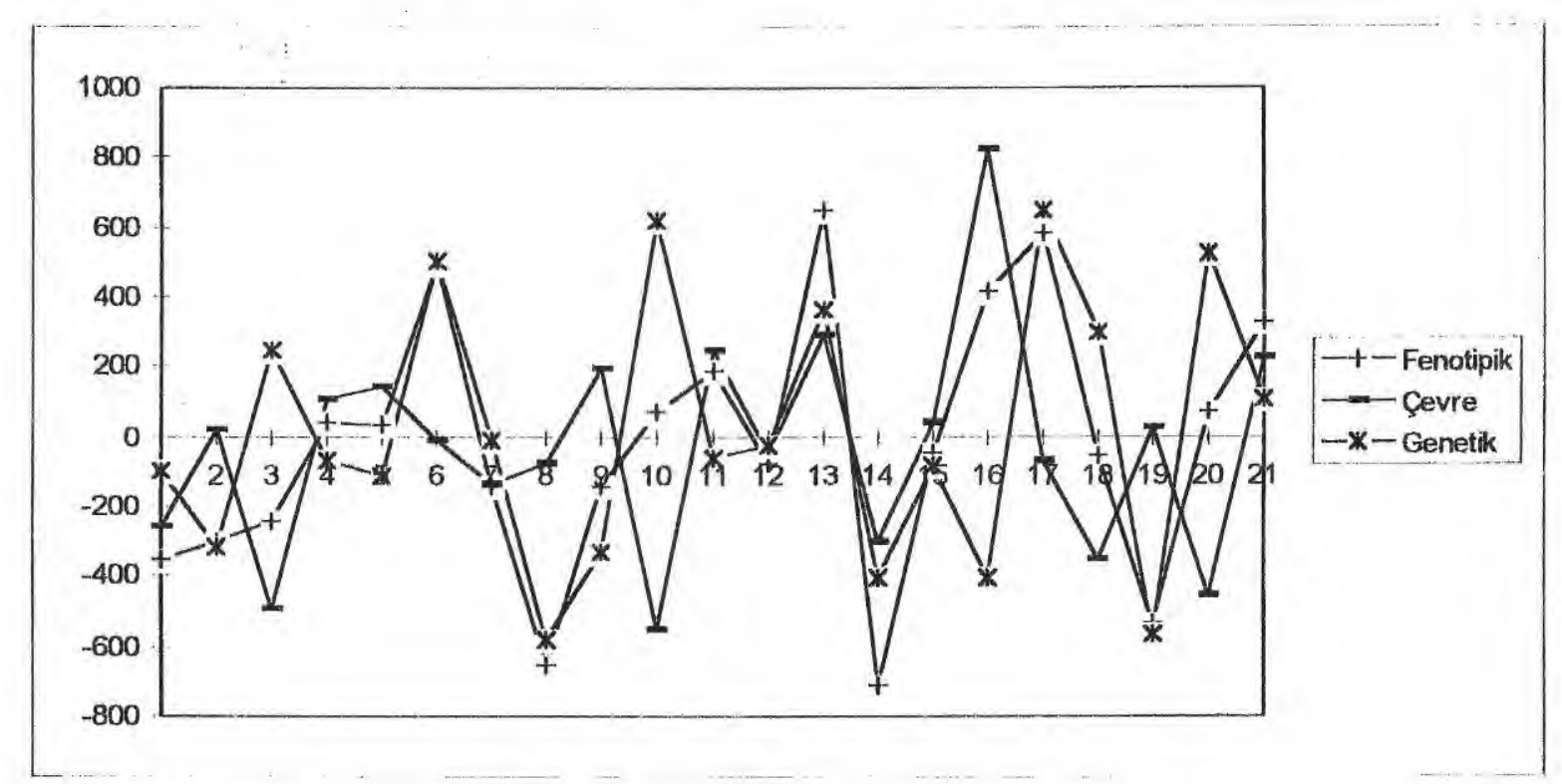

Şekil 1. Tum laktasyon kayıtlarına göre fenotipik, çevresel ve genetik yönelimlerin yıllara göre değişimi

Fenotipik yönelimlerde olduğu gibi çevresel yönelimlerde bazı yıllar negatif bazı yıllar ise pozitif değerler almışlardır. Böylece çevre etkilerinin eklemeli toplamı - $628 \mathrm{~kg}$, yıla düşen etkisi ise - $29,90 \mathrm{~kg}$ bulunmuştur. Başka bir deyişle hayvanlar bir önceki yıla göre ortalama olarak daha düşük verim vermişlerdir. Bu duruma göre; verimler laktasyon sırası ve buzağılama mevsimine göre düzeltildikleri için işletmede çevre faktörlerinin yıldan yıla iyileşmeyip bilakis kötüleştiği anlaşılmaktadır. 
Fenotipik yönelimden çevresel yönelimin çikarılmasıyla genetik yönelim hesaplanmıştır. Buna göre ortalama $-16.95 \mathrm{~kg}$ olarak bulunan fenotipik yönelimden 29.90 kg'lık çevresel yönelimin çıkarılmasıyla 12.95 kg'lık genetik yönelim hesaplanmıştır.

Genetik yönelimlerin eklemeli değerleri 1976-77 yılları hariç tutulacak olursa, hep pozitif olarak kalmıştır. Genetik yönelimlerin eklemeli toplamı $272 \mathrm{~kg}$ olmuş. bunun yila düşen etkisi ise $12.95 \mathrm{~kg}$ olarak gerçekleşmiştir. Bu durum işletmede damızlik seçimi bakımından isabetli davranıldığını, ancak çevre faktörlerindeki kötüleşme nedeniyle verimde ilerlemeler sağlanamadığını göstermektedir.

$\mathrm{Bu}$ araştırmada elde edilen $12,95 \mathrm{~kg}$ 'lık genetik yönelim tahmini, Mc Daniel ve ark. (1961)'in Siyah Alacalar için bildirdiği $71.7 \mathrm{~kg} / \mathrm{yll}$, Arave ve ark.(1964)'ın California Jerseyleri için bildirdiği $33.6 \mathrm{~kg} / \mathrm{y} ı l$, Siyam ve Düzgünes (1984)' in Türkgeldi ve Sarımsaklı Devlet Uretme Çiftliklerinde yetiştirilen Siyah Alacalar için bildirdikleri 78 kg/yıl ve 70 kg/yıl, Lak (1987)'ın Ankara Şeker Çiftliğinde yetiștirilen Esmerler için tüm ve birinci laktasyonlar bildirdiği 158 kg/yıl ve 156 kg/yıl, Gürdoğan ve Alpan (1990)'nın Ankara Şeker çiftliğinde yetiştirilen Siyah Alacalar için bildirdiği $149 \mathrm{~kg} / \mathrm{y}$ ıl değerlerinden düşük, Akar ve Pekel (1988)'in Eskişehir Tohum Üretme Çiftliğindeki Esmer sığırlar için bildirdiği - $53.6 \mathrm{~kg} / \mathrm{y} ı \mathrm{l}$, Dillon ve ark.(1955)'nın Siyah Alacalar için bildirdiği 0.309 kg/yıl, Johnson ve ark.(1956)'nın Siyah Alaca ve Jerseyler için bildirdiği - $34.5 \mathrm{~kg} / \mathrm{yll}$ ve $-12.3 \mathrm{~kg} / \mathrm{yll}$, Gaalas ve Plowman (1961)'nın Siyah Alacalar ıçin bildirdiği - 81 $\mathrm{kg} / \mathrm{yıl}$ değerlerinden yüksek bulunmuştur. Bu değerler aynı zamanda, Arave ve Laben (1963) 'nin Jerseyler için bildirdiği $7.4-84.5 \mathrm{~kg} / \mathrm{y} ı$ l değer aralığının içinde yer almıştır.

\section{Uygulanmış olan seleksiyon sonuçlarına göre yönelim unsurlarının tahmin edilmesi}

Bu metoda göre elde edilen tahminler sürüde uygulanmış olan seleksiyona dayanmaktadır ve bir hayvanın sürüde verim veren yavrusunun olmasına bakilarak karar verilmiştir. Hesaplanan genetik yönelimlerin hangi yıllara ait olduğuna karar verebilmek için hesaplamalara katılan ana ve babaların doğum tarihi ile bunların kızlarının ve oğullarının doğum tarihleri hesaplanmıștır. Buna göre genetik yönelimin hesaplandığı zaman diliminin başlangıç tarihi en yaşlı babanın doğum tarihi olan 1965 yılı, bițş tarihi ise yavru grupları içerisinde en genç kızın (ineğin) doğum tarihi olan 1989 yılı kabul edilmiştir. Söz konusu metodun materyale uygulanması ile tahmin edilen genetik yonelim tahminleri Çizelge 8'de verilmiştir.
Cizelge 8 . Sürüde 305 günluk sü verimi bakımından genetik üstünlük, generasyon aralıkları ve 1965-1989 yılları arasindaki genetik yönelim tahminleri

\begin{tabular}{|c|c|c|}
\hline Gen Nakil Yolu & $\begin{array}{c}\text { Genetik Ustünlük } \\
(\mathrm{kg})\end{array}$ & $\begin{array}{c}\text { Generasyon } \\
\text { Aralığı (Yil) }\end{array}$ \\
\hline Babalardan oğullara & 4.30 & 4.63 \\
\hline Babalardan kızları & -8.17 & 5.50 \\
\hline Analardan oğullara & 318.00 & 6.47 \\
\hline Analardan kızlara & 22.95 & 5.13 \\
\hline Toplam & 337.08 & 21.73 \\
\hline Ortalama & $337.08 / 21.73=15.51 \mathrm{~kg} / \mathrm{y}$ ıl \\
\hline
\end{tabular}

Genetik yönelimin hesaplanmasında olduğu gibi, elde edilen sonuçlarin analizinde de bu 4 gen nakil yolu ayrı ayrı göz önüne alınıp sürüdeki seleksiyon süreci incelendikten sonra yorumlamalar getirilmiştir.

Dört gen nakil yolu birlikte ele alındığında genetik yönelim $15.51 \mathrm{~kg} / \mathrm{yll}$, generasyon arası süre ise $5.6 \mathrm{yıl}$ olarak hesaplanmiştir. Generasyon aralığı için hesaplanan 5.6 yil değeri Siyah Alacalarda tespit edilen 4.2 yıl (Yener ve ark. 1978), Esmer sığıriarda bildirilen 5.3 yil (Yener 1979) değerlerinden uzun ancak, Haryana ırkında bildirilen (Acharya ve Lush, 1968) 7.9 yil, Brezilya Yerli ırkında bildirilen (Brazil ve ark. 1990) 7.0 yil, Çek Alaca sığırlarda bildirilen (Siler ve Sereda 1971) 6.8 yıl, Red Sindhi irkında bildirilen 6.5 yıl (Mahadevan, 1955), Siyah Alaca sığırlarında bildirilen 6.25 yıl (Van Tassell ve Van Vleck, 1991), Norveç Kırmizısı ırkında bildirilen (Syrstad 1966), 6 yıl, Esmer (Lak 1987) sığırlarda bildirilen 5.9 yıl değerlerinden daha kısa bulunmakla beraber, kültür ırklarında olması beklenen süreden yine de uzundur. Bu durum, aynı damızlıkların sürüde uzun süre kullanılmış olmasından kaynaklanmıştır. Generasyon aralığının kısa bulunmuş olması yıllık genetik ilerleme açısından avantajlı bir durumdur.

$1551 \mathrm{~kg} / \mathrm{y}$ it olarak hesaplanan genetik yönelim tahmini Red Sindhi Irkında bildirilen $-11.71 \mathrm{~kg} / \mathrm{y}$ Il (Mahadevan 1955), Siyah Alacalarda bildirilen -2.3 (Yener ve ark.1978), Esmer sığırlarda bildirilen 0.59 (Yener 1979), Yerli Mısır sığırlarında bildirilen $8.2 \mathrm{~kg} / \mathrm{y} ı l$ (Asker ve ark. 1955) değerlerinden yüksek, Çek Alacalarında bildirilen $21.97 \mathrm{~kg} / \mathrm{yil}$ (Siler ve Sereda 1971), Ayrshirelerde bildirilen $30-37 \mathrm{~kg} / \mathrm{yIl}$ (Lindstorm 1968), Norveç Kırmizısı sığırlarda bildiriten $34.32-47.17 \mathrm{~kg} / \mathrm{y}$ il (Syrstad (1966) ve Siyah Alacalarda bildirilen 92 kg/yıl (Gürdoğan ve Alpan 1990) değerlerinden daha düșük bulunmuştur. Diğer taraftan bu araştırmada tespit edilen değer, Ayrshire ırkında bildirilen $15.45 \mathrm{~kg} / \mathrm{yll}$ (Rendel ve Robertson 1950) ve Haryana irkinda bildirilen 16 kg/yil (Acharya ve Lush 1968) değerlerine oldukça yakın bulunmuştur. 


\section{Sonuç ve Öneriler}

Türkiye'de kültür ırkı sığırlar ve bunların yerli ırklarla melezlerinin sayısı gün geçtikçe artmaktadır. Gerek resmi ve gerekse özel kuruluşlarda yüksek verim elde edebilmek amacıyla kültür ırklarına dayalı entansifleşme gün geçtikçe yoğunlaşmaktadır. Ancak, bu hayvanlardan genetik kapasitelerinin elverdiği ölçüde verim alınabilmesi optimum çevre şartlarının sağlanması durumunda mümkändär.

Bu çalışmada Van Tarım Meslek Lisesi işletmesinde yetiştirilen Esmer sığır sürüsünūn 1968-89 yılları arasındaki verim kayıtları analiz edilmiştir. Analizlerde sürü ortalamasındaki yıllar itibarıyla değişmeler ve bu değişmelere genotipik Islah ve çevre değişmelerinin payı ayrı ayrı tahmin edilmeye çalışılmıştır. Uç ayrı metoda göre tahmin edilen genetik yönelimler 11.37 ile 15.51 $\mathrm{kg} / \mathrm{yıl}$ değerleri arasında değişmiştir. Çevresel yönelim ise $-28.55 \mathrm{~kg} / \mathrm{yll}$ olarak tahmin edilmiștir. Bu durum, âc ayrı metoda göre elde edilen genetik yönelim sonuçlarının birbirine yakın olduğu ve elde edilen değerlerin gôvenilir olduğu şeklinde yorumlanabilir. Buna rağmen üçüncŭ metod, sûrüde uygulanan seleksiyonun analiz edilmesini sağladığı ve seleksiyonla sağlanacak genetik ilerlemeyi tahminde kullanılan generasyon aralıklarinı hesaplama fırsatı verdiği için, diğer iki metoda göre daha uygun görülebilir. Fakat 4 gen nakil yolu kullanıldığından bunların herbirine düşen hayvan sayısının azalmasından dolayı elde edilen değerin güvenilirlik derecesinin düşăk olacağını da gözden uzak tutmamak gerekir. Yukarıdaki açıklamalar dikkate alındığı zaman, geniş materyal uzerinde çalışılırsa ikinci metodun daha uygun olacağ söylenebilir. Buna karşılık eğer genetik yönelim az sayıda laktasyon verimine dayandirilarak hesaplaniyorsa, birinci metodun kullanilması tavsiye edilebilir.

Seleksiyon sonuçlarına göre 305 günlük süt verimine ilişkin genetik yönelim $15.51 \mathrm{~kg} / \mathrm{yll}$ olarak bulunmuştur. İşletmede hayvan sayıșının azlığı sebebiyle damızlık seçiminde herhangi bir sistematik seleksiyon yapılmamakta ve hayvanların fenotipik görünüşüne bakılarak seçim yapılmaktadır. Işletmede yem bitkilerine tahsis edilen arazinin artırılması şartıyla sürü de genişletilebilir ve böylece daha etkin bir seleksiyon programı uygulamaya konulabilir. Ancak daha acil bir çözüm olarak da döl kontrolü yapılmış boğalardan sperma getirilerek suni tohumlama uygulamasına hız verilmesi tavsiye edilebilir.

305 günlăk süt verimi sistematik çevre faktörlerine göre düzeltilmiş olmasına rağmen çevre yöneliminin negatif yönde $(-28.55 \mathrm{~kg} / \mathrm{y}$ II) bulunmus olması işletmede bakım, besleme ve idari problemler olduğunun bir göstergesidir. Işletmede mer'aya dayalı hayvancilık yapılmış olması sebebiyle bazı yıllar yağış miktarının azlığından dolayı hayvanlar meradan yeterince yararlanamamış ve bu yıllara ait çevresel yönelimler negatif bulunmuştur. Hem bu çalışmada hem de Türkiye'de kültür ırklarıyla yapılan diğer çalışmalarda ortaya çıkan gerçek şudur ki; yüksek verimli hayvanların talep ettiği çevre sağlanamamaktadır. Entansif süt sığırcılığıyla ilgilenenlerin veya bu alana yatırım yapmayı dūşūnenlerin iyi damızlık bulmak kadar, uygun çevre sağlamak yönünde de çaba sarfetmeleri ve çalışmaları gerekmektedir.

Damızlıkçı niteliğindeki işletmeler genetik ve çevre yönelimleri ne olursa olsun, sürekli seleksiyon yapmak ve seleksiyon üstanlüklerini hesaplamak zorundadır. Çanka bu tip analizler, işletmede şimdiye kadar yapılan uygulamaların başarısını da ölçme imkanı verirler. Nitekim seleksiyon sonuçlarından yararlanılarak hesaplanan genetik ilerlemede çeşitli unsurların payları da bu şekilde değerlendirilir. Daha önce belirtildiği gibi babalardan oğullara ve babalardan kızlara sağlanan seleksiyon ustanlüğü sırasıyla $4.30 \mathrm{~kg}$ ve $-8.17 \mathrm{~kg}$ 'dır. Analardan oğullara ve analardan kızlara sağlanan genetik seleksiyon üstünlükleri ise sırasıyla $318.00 \mathrm{~kg}$ ve 22.95 kg'dır. Buradan da görüleceği gibi toplam $15.51 \mathrm{~kg}$ ilerlemenin \% 1.27'ini boğa babalarının seçimi, \% 2.42'sini inek analarının seçimi, \% 94.35'ûnū boğa analarının seçiminden, \% 6.81'ini inek analarının seçimiyle sağlanmıştır.

Diğer taraftan, süt ve döl verimine ilişkin kalıtım derecesi ve tekrarlanma dereceleri tahmin edilmiştir. Sût verimine ilişkin kalıtım derecelerinin orta-yüksek, tekrarlanma derecelerinin ise yûksek bulunmuş olması seleksiyonun ilk laktasyon kayıtlarına göre yapılabileceğine önemli bir işarettir.

\section{Kaynaklar}

Acharya, R.M and J.L. Lush, 1968. Genetic Progress Through Selection in a Closed Herd of Indian Cattle. J. Dairy Sci. 51 : 1059-1064.

Akar, M ve E. Pekel, E., 1988. Türkiye Seker Fabrikalan A.S. Eskişehir Tohum Urefme Ciftiöinde Yetiștirilen Saf ve Melez Esmer Sığmrlarn Süt Verimindeki Genetik ve Fenotipik Yönelimler ile Bazı Parametrelerin Tahmin Üzerinde Bir Araşırma. Cuk. Univ. Zir. Fak. Derg., 3:51-65.

Akbulut, Ö., 1992. Atatürk Üniversitesi Tarum Işletmesinde Yetiştirilen Esmer, Ileri Kan Dereceli Esmer ile Siyah Alaca Sığırların Süt Verim Özellikleri ve Laktasyon Eğrisi Parametrelerine Etkili Faktörler. A.0̂. Fen Bilimleri Enst. (Doktora Tezi), Erzurum.

Arave, C.W., R.C. Laben and S.W. Mead, 1964. Measurement of Genetic Change in Twelwe California Dairy Herds. J. Dairy Sci. $47: 278-283$. 
Arave, C.W and R.C. Laben, 1963. Study of Genetic Progress in California Dairy Herds, J. Dairy Sci. $46: 629$.

Asker, A.A., M.T., Ragab and S.A. Hilmy, 1955. Genetic Improvement in Milk Yield in Two Herds of Cattle and Buffaloes in Egypt. Indian J. of Anim. Sci $8: 39-46$

Brasil, L.H. De A., J.C.C. Pereira, C.S., Pereira and H.N. De Oliveira, 1990. Generation Interval and the Annual Genetic Trend in Body Weight at $\mathbf{3 6 5}$ days of Age in a Herd of Nelore Cattle. Arquivo Brasileiro de Medicina Veterinaria e Zootecnia, 42 ; 57 66.

Dillon, W.M., Jr. W.W. Yapp and R.W. Touchberry, 1955. Estimates Changes in the Environmental and Average Real Procuding Ability in a Holstein from 1901 through. J. Dairy. Sci. $38: 616$.

Galaas, R.F and A.D. Plowman, 1961. Effectiveness of Statistical Adjustrnents for Yearly Fluctuations in Production. J. Dairy Sci. 44: 1188. Arave, C.W and R.C. Laben, 1963. Study of Genetic Progress in California Dairy Herds. J. Dairy Sci. 46 : 629.

Gönul, T ve Ir. M.P.M. Vos, 1966. Friesianlarda (Siyah Alaca Sığırlarda) Süt ve Yağ Veriminin Çevresel Faktörlere Bağlı Olarak Değişimi, Kalıtım Derecesi Tahminleri ve Bu Karakterler Arasındaki Genetik ve Fenotipik İlgiler Úzerinde Araştırmalar. Ege Üniv. Ziraat Fak. Derg. 3 (1) 73-92.

Gürdoğan, T ve O. Alpan, 1990. Ankara Şeker Fabrikası Çiftliğinde Yetiştirilen Holştayn Sürüsünde Süt Verimine ilişkin Genetik Parametreler ve Genetik ilerleme Hizı. A.U. Vet. Fak. Derg. 37 : 101-115.

Harvey, W.R., 1960. Least Squares Analysis of Data With Unequal Subclass Numbers, Agric. Res. Ser., USDA, ARS. Arave, C.W and R.C. Laben, 1963. Study of Genetic Progress in California Dairy Herds. J. Dairy Sci. 46 : 629.

Herbert, S and D.S. Bhatnagar, 1988. Genetic Trends of Economic Traits in Dairy Cattle : A Review. Agricultural Reviews. 9 : 200-216.

Inal, Ş, 1988. Konya Merkez Hayvancılık Araştırma Enstitüsündeki Esmer Irk Sığırlarda Bazı Döl Verim Özellikleri. Ank. Üniv. Sağ. Bil Enst. (Doktora Tezi), Ankara.

Johnson, K.R., D.O. Everson and W.R. Taylor, 1956. The Importance of Heredity and Environment in Causing Variation in D.H.I.A. Records Made in Idaho. J. Dairy Sci. 39: 1482.

Juma, K.H., T.R., Saad and A.L. Tikriti, 1990. Performances of Brown Swiss and Friesian in Central Iraq, Proceedings of the 4 th World Congress on Genetics Applied to Livestock Production. XV. Beef Cattle, Sheep and Pig Genetic and Breeding, 23-27 July, Edinburgh.

Lak, A., 1987. Şeker Çiftliği Esmer Sığırlarınin Genetik Analizi. A.Ü. Fen Bilimleri Enstitüsü, Doktora Tezi, Ankara.

Arave, C.W and R.C. Laben, 1963. Study of Genetic Progress in California Dairy Herds. J. Dairy Sci. 46 : 629.

Lindstörm, $U, 1968$. Estimation of Genetic Changes in Artificially Bred Populations of Finnish Dairy Cattle. 1. Genetic Change in Populations of Ayrshire Breed in 1961-1966. viit174 pp. Eng. With Finn. Summ. Eng and Finn. Tables.

Manadevan, P, 1955. Population and Production Characteristics of Red Sindhi Cattle in Ceylon. J. Dairy Sci. $38: 1231$ 1241.

McDaniel, B.T., R.D. Plowman and R.F. Davis, 1961. Causes and Estimation of Enviromental Change in a Dairy Herd. J. Dairy Sci. 44 : 699-707.

Meija, N.A., J.C. Milagres, M.DE.A.E. Silva and A.C.G. Castro, 1982. Effect of Genetic and Environmental Factors on Calving Interval in Brown Swiss and Holstein Friesian Caws in Central America (Honduras). Revista da Sociedale Brasileira de Zootecnica. 11 : 307-319.

Oishi, T., K. Shimada, A. Okano and Y. Izaike, 1983. Genetic Studies on Reproductive Characters in Japanese Black Cows. 1. Gestation Length, Calving Interval and Number of Inseminations per Conception. Bulletin of the Chugoku National Agricultural Experiment Station, $27: 1-8$

Pyshechkin, N.P, 1988. The Effect of Genotype of Bulls on the Relationships Among Dairy Traits in Their Daughters and Repeatability of Traits. Sbornik Nauchnykh Trudov.Vsesoyuznoe Nauchno Proizvodst Ven Noe Ob" edineniepo Plemennomu Delu v Zhivotnovododstve, 32-35.

Rendel, J.M and A. Robertson, 1950. Estimation of Genetic Gain in Milk Yield by Selection in a Closed Herd of Dairy Cattle. J. Genetics, $50: 21-31$

Siler, R and L. Sereda, 1971. The Estimation of Genetic Gain in Milk Production of Czech Pied Cattle. Zivocisna Vyroba $16: 177$ 184.

Siyam, V and O. Düzgüneş, 1984. Trakya Devlet Kuruluşlarinda Yetiştirilen Siyah Alaca Sığır Sürülerinde Süt Verimi Bakımından Genotipik ve Fenotipik Yönelimier " A.U. Fen Bilimleri Enst. No : ZT.3, Ankara.

Syrstad, O. 1966. Studies on Dairy Herd Records. III. Estimation of Genetic Change. Acta Agr. Scand. $16: 3-14$.

Talan. O. 1989. Sığırlarda Değişik Süt Verim Kontrol ve Hesaplama Yơntemleri Üzerinde Araştırmalar. Ç.Ü. Fen Bilimleri Enst. Zootekni Anabilim Dalı (Yaksek Lisans Tezi)

Ulusan, H.O.K, 1988. Esmer Sığırlarda Süt Verimi, Laktasyon Süresi ve Kuruda Kalma Süresinin Tekrarlanma Dereceleri A.Ü. Vet. Fak. Derg. $35(2-3): 253-259$.

Ulussan, H.O.K ve M. Özçelik, 1988. Esmer Sığırlarda Sü Verimi ve Laktasyon Süresinin Kalıtım Dereceleri ve Aralarindaki Genetik ve Fenotipik Korelasyonları. A.U. Vet. Fak. Derg. $35(2-3): 260-268$.

Van Tassell, C.P and Van Vleck, L.D. 1991. Estimates of Genetic Selection Differentials and Generation Intervals for Four Paths of Selection. J. Dairy Sci. 74:1078-1086.

Vanli, Y., M.K. Özsoy, M.K ve S. Baș, 1993. Populsyon ve Biyometrik Genetik. Y.Y.Ü. Ziraat Fak. Yay. No:4, Van.

Yener, S.M., 1979. Orta Anadolu Devlet Üretme Çiftliklerinde Esmer Sığırların Süt Verimindeki Genetik Yönelimler. A.Ü Zir. Fak. Hawan Yetiștirme ve Islahi Kursüsü, Ankara.

Yener, S.M., E. Tuncel ve M. Eker, 1978. Atatürk Oman Çiftliğinde Yetiştirilen Siyah Alaca Sığırların Süt Veriminde Genetik Yönelim. A. U.Zir. Fak. Yıllığı, $28: 819-831$. 